\title{
A method of value measurement based on probability theory in economics
}

\author{
Gang Xi ( $\nabla$ carlxi@live.com ) \\ Vancouver Community College \\ Xiaoyi Yang ( 0 592974351@qq.com ) \\ School of Economics \& Management, Xidian Universty \\ Ming Xi ( $\nabla$ szxm1998@126.com) \\ School of Humanities, Shenzhen Polytechnic
}

\section{Method Article}

Keywords: value, price, random variables, measurement

Posted Date: March 30th, 2021

DOI: https://doi.org/10.21203/rs.3.rs-364242/v2

License: (c) (1) This work is licensed under a Creative Commons Attribution 4.0 International License. Read Full License 


\title{
A method of value measurement based on probability theory in economics
}

\author{
Gang $\mathrm{Xi}^{1}{ }^{1}$ Xiaoyi Yang, ${ }^{2}$ Ming Xi ${ }^{3}$
}

\begin{abstract}
Value is one of the most fundamental concepts in economics. The existing main definitions of value have certain limitations and are difficult to be unified and quantified. Thus, this article presents a method of quantifying value based on the conditional probability theory; we set value as a random variable, a price is the value of the good in terms of money, according to the price' $s$ historical records, quantitative statistics and human experiences, and thus uses conditional probability distribution to measure value. Furthermore, the mean and variance of random variables are used to describe the weighted average of the possible values and the dispersion of values distribution. This method provides a new perspective for the measurement of value.
\end{abstract}

\section{Introduction}

"Economics is the study of how society uses scarce resources to produce valueable goods and services, and distribute them among different individuals." The term value that will be referred in this context only defines the value of commodities, including goods and services. So what is the value of commodities? How do we exactly measure it?

Throughout the history, economists concluded various definitions of value based on the criterion of their hypothesis. When Adam Smith utilizes exchange and usage as the criteria, he determined in the book The Wealth of Nation, "the word value, it is to be observed, has two different meanings, and sometimes expresses the utility of some particular objects, and sometimes the power of purchasing other goods which the possession of that object conveys." ${ }^{2}$ However, if the commodity has not been exchanged or used, then Smith's theory would not fit when examining a commodity's value. Meanwhile, Karl Marx defined value through the labour-time socially necessary for a commodity's production; Marx wrote in the Capital "the common substance that manifests itself in the exchange-value of commodities, whenever they are exchanged, is their value" and "as values, all commodities are only definite masses of congealed labour-time." " In fact, socially necessary labour time is too broad and abstract in the real world social interaction, causing it very difficult to manifest the result. It is hardly possible to examine value through socially necessary labour time as every person's ability varies, and consequently difficult to provide a unified measure and standard. From a different angle, Alfred Marshall uses time and place as the precedent and determines value based on their relationship; his concern was "the term value is relative, and expresses the relation between two things at a particular place and time." ${ }^{4}$ It is without doubt that if the conditions of time and space have been met, we could determine the values of two things when successfully seeking a visible connection between them. However, if we were only using time and place as the two criteria, it would be an illogical study, indeed, an incomplete one. Since the criterion and definition of value vary in the perspectives of well-known economists throughout the time, is it possible that we could construct an uniform method, that revolves around mathematics to measure commoditiy's value and eliminate any ambiguity within values? This is the purpose of this article.

With the rising economic practices in recent years, it came with the urgent needs of understanding the inevitable laws and regularities implied in various uncertain phenomena, and discovering the possibility of various results using mathematical methods. "The essential feature of modern eonomic theories is that it is analytical and mathematical." ${ }^{5}$ According to the given assumptions and logical derivation, probability theory and mathematical statistics can obtain corresponding measurement conclusions, thus becoming effective tools to forecast and analyze economic operation.

The perfection and maturaity of mathematics tools such as probability theory and mathematical statistics were completed only decades ago. Even if previous economists had acutely realized that value is the essential feature in all economic activities and used various methods from diverse perspectives to define the concept of value, there were no opportunities of applying probability theory to actual practices of examining value. Thus, all the discussions regarding value remained relatively on the abstract or philosophical level and had certain historical limitations. Reversely, in this study, we define value as random variables, and provide a unified value measurement method by using conditional probability theory and mathematical statistics. This method quantifies the measurement of value, so that we can understand the value more clearly and comprehensively, and make the measurement of value operable in economic activities.

\section{Definition}

Almost all economic activities are conducted under certain historial and social background. While measuring their values, we need to take into consideration of their context and conditions, including but not limited to scarcity, homoeconomicus or rational man, time, place, usage, exchange, labour, and conditions. When we are provided with certain conditions hether consciously or not, we need to base off them on the existing criteria, the value's historical records, quantitative statistics and human experiences to derive a probability distribution of values interval and provide an accurate or approximate mathematical description.

How can we acquire the value's historical records, quantitative statistics and human experience? Although different economists have endowed value with dissimilar connotation, there is a consensus that value is always presented in the form of price. The commodity is then sold precisely for what it is value, Smith considers "When the price of any commodity is neither more nor less than what is sufficient to pay the rent of the land, the wages of the labour, and the profits of the stock employed in raising, preparing, and bringing it to market, according to their natural rates, the commodity is then sold for what may be called its natural price. The commodity is then sold precisely for what it is worth, or for what it really costs the person who brings it to market." Marx wrote in the Capital "The elementary expression of the relative value of a single commodity, such as linen, in terms of the commodity, such

${ }^{1}$ EAL, Vancouver Community College, 1155 East Broadway, Vancouver, B.C. V5T 4V5, Canada. ${ }^{2}$ School of Economics \& Management, Xidian Universty, 266 Xinglong Section of Xifeng Road, Xi' an, Shaanxi 710126, China. ${ }^{3}$ School of Humanities, Shenzhen Polytechnic, Liuxian Avnue 7098, Nanshan Distrect, Shenzhen, Guangdong, 518055, China. Correspondence and requests for materialsshould be addressed to G.X. (email: 


\section{carlxi@live.com)}

as gold, that plays the part of money, is the price form of that commodity" Meanwhile, he challenged the perspective of separating value and exchange value as two entities, "the value of commodity obtains independency and definite expression through the form of exchange value. When, at the beginning of this chapter, we said, in common parlance, that a commodity is a use value or object of utility, and a value." "Alfred Marshall concern was "Civilized countries generally adopt gold or silver or both as money. Instead of expressing the values of lead and tin, and wood, and corn and other things in terms of one another, we express them in terms of money in the first instance; and call the value of each thing to express its price." It is undoubtedly that Marshall also concluded that price is the currency representation of commodity value, which aligns with the modern economics' point of view. "Thus the price of anything will be taken as the representation of its exchange value relatively to things in general." "Samuelson considers "The central role of markets is to determine the price of goods. A price is the value of the good in terms of money." During the initial formation stage of economics principles, the central purpose was liberating trade and industry from the shackle of feudalism. Nowadays, Industrial and trade liberalization is intertwined with government intervention, the automation of technology and services are strengthening, the commodity value is being exchanged more freely and frequenrly worldwide, information technology and computer science can accurately measure and record commodity transaction and values, and these technical improvements all set the stag e to measure commodity value more efficiently and effectively. Consequently, we can successfully measure commodity value based on the commodity's historical price and human experience.

In economics, we define value as a random variable, in other words, the price is a random variable too. $P(E)$ represents the probability that the commodity's value is $E$, that is to say, the degree of confirmation or statistical frequency that the commodity's value is $E$. In addition, the various preconditions of value are collectively referred to as $F$. Certainly, $F$ may be a compound condition, that is, a combination of multiple conditions, which is called condition $F$. Furthermore, condition $F$ must include the hypotheses of resource scarcity and homoeconomicus. These two conditions are only regarded as implicit conditions when considering the value measurement, and are often not specially marked.

In order to facilitate the discussion of value measurement, the classical definition of probability is given: (See reference 7 for specific definitions)

We shall assume that for each event $E$ of an experiment having a sample space $S$, there is a number, denoted by $P(E)$, that is in accord with the following three axioms.

\section{AXIOM 1}

\section{AXIOM 2}

$$
0 \leq P(E) \leq 1
$$

$$
P(S)=1
$$

AXIOM 3

For any sequence ofmutually exclusive events $E_{1}, E_{2}, \ldots$ (that is, events for which $E_{i} E_{j}=\emptyset$ when $i \neq j$ ),

$$
\mathrm{P}\left(\cup_{i=1}^{\infty} E_{i}\right)=\sum_{i=1}^{\infty} P\left(E_{i}\right), \quad n=1,2, \ldots, \infty
$$

We call $P(E)$ the probability of the event $E$.

Thus, Axiom 1 states that the probability that the outcome of the experiment is contained in $E$ is some number between 0 and 1. Axiom 2 states that, with probability 1, the outcome will be a member of the sample space $S$. Axiom 3 states that for any set of mutually exclusive events the probability that at least one of these events occurs is equal to the sum of their respective probabilities.

The relationship between two random variables can often be clarified by consideration of the conditional distribution of one given the other.

Recall that for any two events $E$ and $F$, the conditional probability of $E$ given $F$ is defined, provided that $P(F)>0$, by

$$
P(E \mid F)=\frac{P(E F)}{P(F)}
$$

\section{Methods}

We use the conditional probability distribution of random variables to measure the value of commodity and joint commodity. For the sake of clarity, we give examples of commoditiy $\mathrm{C} 1$ and $\mathrm{C} 2$ and the joint commodity $\mathrm{C} 1+\mathrm{C} 2$.

Value Variables. In this paper, we use discrete random variables to represent random variables of value (value variables). For a discrete random variable $X$, we define the probability mass function $p(a)$ of $X$ by

$$
p(a)=P\{X=a\}
$$

The probability mass function $p(a)$ is positive for at most a countable number of values of a. That is, if $X$ must assume one of the values $x_{1}, x_{2}, \ldots$, then

$$
\begin{array}{ll}
p\left(x_{i}\right)>0, & i=1,2, \ldots \\
p(x)=0, & \text { all othere values of } x
\end{array}
$$

Since $X$ must take on one of the values $x_{i}$, we have

$$
\sum_{i=1}^{\infty} P\left(x_{i}\right)=1
$$

The most precise way to determine a population's conditional distribution is taking into accounts of all elements in the population. However, we know in the real social and economic activities for most cases, due to the limitation of cost and other realistic conditions, it is impossible and unnecessary to collect the values of all elements. We can only collect a range of elements for approximate measurement. In experiment, we usually collect sampling statisitics, which are obtained from various sourcrs to 
form a sampling distribution. When samples are surveyed, the observed sample distribution can be used to approximate the population distribution. There are mature methods to determine the accuracy of approximation in mathematical statistics, so we will not reiterate the specifics here.

As shown below, Table 1 and 2 are frequency table sfor a data set consisting of $\mathrm{C} 1$ and $\mathrm{C} 2$ 's value. $p_{X}$ and $p_{Y}$ are the probability mass functions of $X$ and $Y . X$ and $Y$ are the value variables of commodity $\mathrm{C} 1$ and $\mathrm{C} 2$, such as $-2,0$, 5, etc. $p_{n}$ is the probability, when value is $x_{n}$, such as the probability is $1 / 32$, when that C1's value is 1 .

Table 1 Distribution series of C1's value

\begin{tabular}{|c|c|c|c|c|c|c|c|c|}
\hline$X$ & -2 & -1 & 0 & 1 & 2 & 3 & 4 & 5 \\
\hline$P\left\{X=x_{n}\right\}$ & $\frac{1}{32}$ & $\frac{1}{32}$ & $\frac{1}{16}$ & $\frac{1}{8}$ & $\frac{1}{2}$ & $\frac{1}{8}$ & $\frac{1}{16}$ & $\frac{1}{16}$ \\
\hline
\end{tabular}

Table 2 Distribution series of C2's value

\begin{tabular}{|c|c|c|c|c|c|c|c|c|}
\hline$Y$ & -1 & 0 & 1 & 2 & 3 & 4 & 5 & 6 \\
\hline$P\left\{Y=y_{k}\right\}$ & $\frac{1}{64}$ & $\frac{1}{64}$ & $\frac{1}{32}$ & $\frac{1}{16}$ & $\frac{1}{4}$ & $\frac{1}{4}$ & $\frac{1}{4}$ & $\frac{1}{8}$ \\
\hline
\end{tabular}

For straightforward illustration, we use the following histogram to portray C1's value distribution (when under certain conditions; we could ignore the preceding conditions when they are known to people, and they do not affect our discussion of relevant problems.)
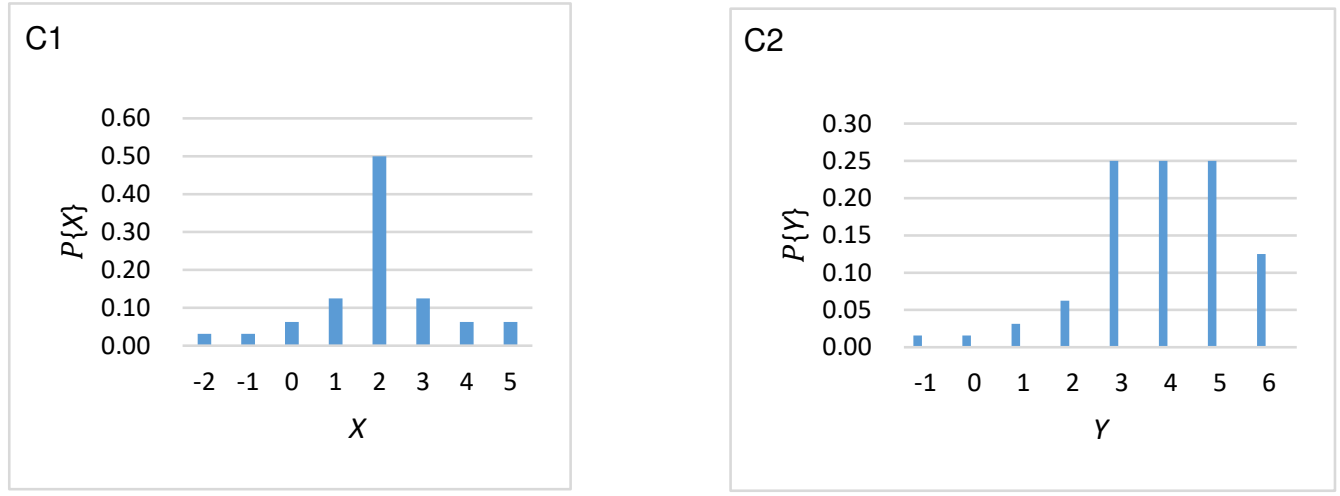

Figure 1. All possible $C 1$ 's value variable $X$ is $-2,-1,0,1,2,3,4,5$ and corresponding probability distribution $P\{X\}$ is $1 / 32$, $1 / 32,1 / 16,1 / 8,1 / 2,1 / 8,1 / 16,1 / 16$. All possible $C 2$ 's value variable $Y$ is $-1,0,1,2 、 3,4,5,6$ and corresponding probability distribution $P\{Y\} \quad$ is $1 / 64,1 / 32,1 / 32,1 / 16,1 / 4,1 / 4,1 / 4,1 / 8$.

We could observe that $\mathrm{C} 1$ 's minimum value is -2 , maximum value is 5 , smallest probability is $1 / 32$, and biggest probability is $1 / 2$. C2's minimum value is -1 , maximum value is 6 , the smallest probability is $1 / 64$, the biggest probability is $1 / 4$. In real economic activities, just illustrating the probability distribution is not sufficient enough to discuss the problem. Hence, we need to introduce a few numerical features of the probability distribution of random variables, and these features are beneficial in terms of enhancing the understanding towards value.

Mean measure. In probability theory, when we discuss the value of a random variable, we need to grasp its numerical features such as mathematical expectation and variance, etc. These could reflect the random variable's certain charaterisitcs in order to better comprehend and compare the random variables. For instance, mathematical expectation illustrates a random variable's mean, so called the expectation or mean. When we measure the value distribution's mean value, it is the population mean, or expectation. In other words, the expected value of $X$ is a weighted average of the possible values that $X$ cantake on, each value being weighted by the probability that $X$ assumes it.

If $X$ is a discrete random variable taking on the possible values $x_{1}, x_{2}, \ldots$, then the expectation or expected value of $X$, denoted by $E[X]$, is defined by

$$
E(X)=\sum_{i} x_{i} P\left\{X=x_{i}\right\}
$$

Computer C1's mean $E(X)$ and C2's mean $E(Y)$ :

$$
\begin{aligned}
& \mathrm{E}(X)=1 \frac{31}{32} \\
& \mathrm{E}(Y)=3 \frac{57}{64}
\end{aligned}
$$




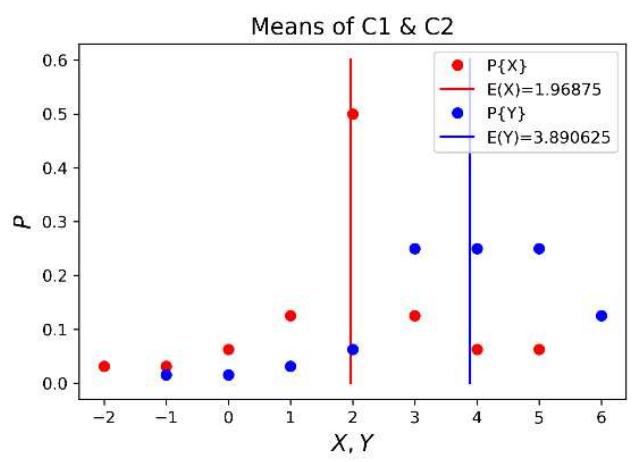

Figure 2. The value distribution of $\mathrm{C} 1$ and $\mathrm{C} 2$ closely gather around the mean of value of 1.96875 and 3.890625 (red and blue line).

In Fig. 2, the red points are the probability distribution of values for $\mathrm{C} 1$, the red vertical line represents its mean value of 1.96875 , the blue points are the probability distribution of values for $\mathrm{C} 2$, and the blue vertical line is its mean value of 3.890625 . The presented data more accurately reflect the recognition level or confirmation degree of $\mathrm{C} 1$ and $\mathrm{C} 2$ values. By comparing the mean values, we can see that under normal conditions, the average value of $\mathrm{C} 1$ is 1.96875 , which is less than that of $\mathrm{C} 23.890625$. It can also be said that under given conditions, the value of $\mathrm{C} 2$ is greater than that of $\mathrm{C} 1$. The value size here usually refe rs to the average value; of course, this does not mean that the value of $\mathrm{C} 2$ must be greater than $\mathrm{C} 1$.

Variance Measure. We use variance to inspect the stability or degree of dispersion of individuals to the value of a commodity. Variance reflects the characteristic of the dispersion of any random variables around the mean. From knowing the features of the random variable, we could compare the measures of dispersion of commodities' value from comparing probability functions of different random variables.

Variance is to describe the degree of sample separation by calculating the distance between the sample and the average value. The greater the difference between the data, the greater the variance; vice versa, the more convergence between the data, the smaller the variance. If the variance is zero, the value will be scalar. There will be no difference in the value in economic activit ies, and the value measurement will lose its practical significance. We use variance to investigate the dispersion degree of commodity values relative to the mean value, so as to compare the concentration or dispersion of different commodity values.

If $X$ is a random variable with mean $\mu$, then the variance of $X$, denoted by $\operatorname{Var}(X)$, is defined by

$$
\operatorname{Var}(X)=E\left[(X-\mu)^{2}\right]
$$

An alternative formula for $\operatorname{Var}(X)$ can be derived as follows:

$$
\operatorname{Var}(X)=E\left[X^{2}\right]-E([X])^{2}
$$

Compute $\operatorname{Var}(X)$ or $\operatorname{Var}(Y)$ when $X$ or $Y$ represents the outcome of $\mathrm{C} 1$ or C2's value variable.

$$
\begin{gathered}
\operatorname{Var}(X)=2 \frac{95}{1024}=2 \frac{380}{4096} \\
\operatorname{Var}(Y)=2 \frac{655}{4096}
\end{gathered}
$$

Jointly Value Measure. Real economic activities are complicated and the combined value of two or more commodities should also be considered. Here, we consider the combination value measure of two commodities, and the combination of multiple commodities can be analogized. Therefore, it is necessary to introduce the definition of two-dimensional joint probability function.

For a given experiment, we are often interested not only in the probability distribution functions of individual random variables but also in the relationships between two or more random variables.

To specify the relationship between two random variables, we define the joint cumulative probability distribution function of $X$ and $Y$ by

$$
F(x, y)=P\{X \leq x, Y \leq y\}
$$

In the case where $X$ and $Y$ are both discrete random variables whose possible values are, respectively, $x_{1}, x_{2}, \ldots$, and $y_{1}$, $y_{2}, \ldots$, we define the joint probability mass function of $X$ and $Y, p\left(x_{i}, y_{j}\right)$, by

$$
p\left(x_{i}, y_{j}\right)=P\left\{X=x_{i}, Y=y_{j}\right\}
$$

The random variables $X$ and $Y$ are said to be independent if for any two sets of real numbers $A$ and $B$

$$
P\{X \in A, Y \in B\}=P\{X \in A\} P\{Y \in B\}
$$

In other words, $X$ and $Y$ are independent if, for all $A$ and $B$, the events $E_{A}=\{X \in A\}$ and $E_{B}=\{Y \in B\}$ are independent. 
When $X$ and $Y$ are discrete random variables, the condition of independence Equation (5) is equivalent to

$$
\mathrm{p}(x, y)=p_{X}(x) p_{Y}(y) \quad \text { for all } x, y
$$

where $p_{X}$ and $p_{Y}$ are the probability mass functions of $X$ and $Y$. The equivalence follows because, if Equation (5) is satisfied, then we obtain Equation (6) by letting $A$ and $B$ be, respectively, the one-point sets $A=\{x\}, B=\{y\}$.

We use $\mathrm{C} 1+\mathrm{C} 2$ to represent the combination of commodity $\mathrm{C} 1$ and commodity $\mathrm{C} 2$, because the value variable of commodity $\mathrm{C} 1$ and the value variable of commodity $\mathrm{C} 2$ are independent of each other:

Table 3 Joint distribution series of C1's and C2's value

\begin{tabular}{|c|c|c|c|c|c|c|c|c|}
\hline$P\left(x_{n}, y_{k}\right)$ & -1 & 0 & 1 & 2 & 3 & 4 & 5 & 6 \\
\hline-2 & $\frac{1}{2048}$ & $\frac{1}{2048}$ & $\frac{1}{1024}$ & $\frac{1}{512}$ & $\frac{1}{128}$ & $\frac{1}{128}$ & $\frac{1}{128}$ & $\frac{1}{256}$ \\
\hline-1 & $\frac{1}{2048}$ & $\frac{1}{2048}$ & $\frac{1}{1024}$ & $\frac{1}{512}$ & $\frac{1}{128}$ & $\frac{1}{128}$ & $\frac{1}{128}$ & $\frac{1}{256}$ \\
\hline 0 & $\frac{1}{1024}$ & $\frac{1}{1024}$ & $\frac{1}{512}$ & $\frac{1}{256}$ & $\frac{1}{64}$ & $\frac{1}{64}$ & $\frac{1}{64}$ & $\frac{1}{128}$ \\
\hline 1 & $\frac{1}{512}$ & $\frac{1}{512}$ & $\frac{1}{256}$ & $\frac{1}{128}$ & $\frac{1}{32}$ & $\frac{1}{32}$ & $\frac{1}{32}$ & $\frac{1}{64}$ \\
\hline 2 & $\frac{1}{128}$ & $\frac{1}{128}$ & $\frac{1}{64}$ & $\frac{1}{32}$ & $\frac{1}{8}$ & $\frac{1}{8}$ & $\frac{1}{8}$ & $\frac{1}{16}$ \\
\hline 3 & $\frac{1}{512}$ & $\frac{1}{512}$ & $\frac{1}{256}$ & $\frac{1}{128}$ & $\frac{1}{32}$ & $\frac{1}{32}$ & $\frac{1}{32}$ & $\frac{1}{64}$ \\
\hline 4 & $\frac{1}{1024}$ & $\frac{1}{1024}$ & $\frac{1}{512}$ & $\frac{1}{256}$ & $\frac{1}{64}$ & $\frac{1}{64}$ & $\frac{1}{64}$ & $\frac{1}{128}$ \\
\hline 5 & $\frac{1}{1024}$ & $\frac{1}{1024}$ & $\frac{1}{512}$ & $\frac{1}{256}$ & $\frac{1}{64}$ & $\frac{1}{64}$ & $\frac{1}{64}$ & $\frac{1}{128}$ \\
\hline
\end{tabular}

According to the joint distribution of value variables of commodity $\mathrm{C} 1$ and commodity $\mathrm{C} 2$, the probability distribution of value variables of $\mathrm{C} 1+\mathrm{C} 2$ can be calculated as follows:

Table 4 Distribution series of $\mathrm{C} 1+\mathrm{C} 2$ 's value

\begin{tabular}{|c|c|c|c|c|c|c|c|c|c|c|c|c|c|c|c|}
\hline$X+Y$ & -3 & -2 & -1 & 0 & 1 & 2 & 3 & 4 & 5 & 6 & 7 & 8 & 9 & 10 & 11 \\
\hline$P(X+Y)$ & $\frac{1}{2048}$ & $\frac{1}{1024}$ & $\frac{5}{2048}$ & $\frac{3}{512}$ & $\frac{11}{512}$ & $\frac{17}{512}$ & $\frac{59}{1024}$ & $\frac{49}{512}$ & $\frac{191}{1024}$ & $\frac{103}{512}$ & $\frac{49}{256}$ & $\frac{1}{8}$ & $\frac{3}{64}$ & $\frac{3}{128}$ & $\frac{1}{128}$ \\
\hline
\end{tabular}

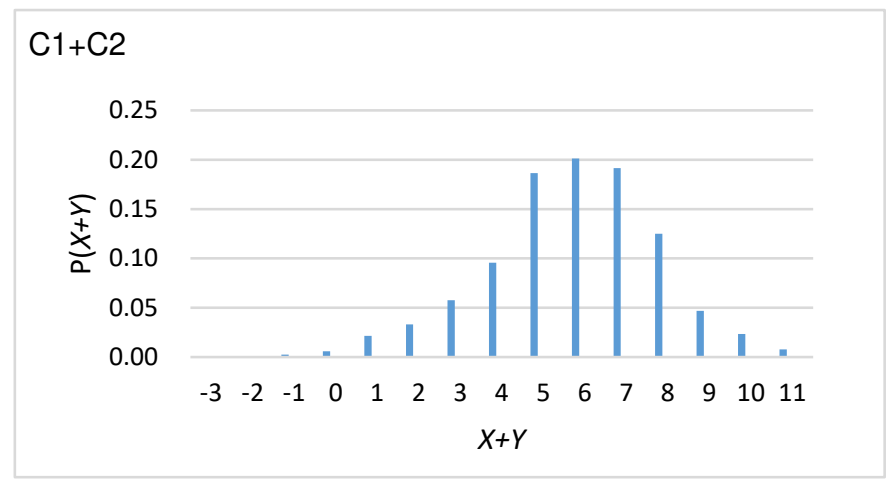

Figure 3. All possible numeric of $\mathrm{C} 1+\mathrm{C} 2$ 's value variable is- $3,-2,-1,0,1,2,3,4,5,6,7,8,9,10,11$ and corresponding probability distribution is $1 / 2048,1 / 1024,5 / 2048,3 / 512,11 / 512,17 / 512,59 / 1024,49 / 512,191 / 1024,103 / 512,49 / 256,1 / 8,3 / 64,3 / 128$, $1 / 128 . \mathrm{C} 1+\mathrm{C} 2$ 's smallest probability is $1 / 2048$, as value is -3 ; biggest probability is $103 / 512$, as value is 6 .

Computer $\mathrm{E}(X) 1.96875+\mathrm{E}(\mathrm{Y}) 3.890625=\mathrm{E}(X+Y) 5.859375$, when $\mathrm{C} 1+\mathrm{C} 2$, greater than the individual mean of $\mathrm{C} 1$ and $\mathrm{C} 2$; $\operatorname{Var}(X) 2.092773+\operatorname{Var}(Y) 2.159912=\operatorname{Var}(X+Y) 4.252685$, greater than the individual variance of $\mathrm{C} 1$ and $\mathrm{C} 2$.

\section{Discussion}

To sum up, the value variable is a discrete random variable. If all situations are taken into account, the value variable will definitely occur, and the probability is 1 , that is $100 \%$. In fact, a value variable can not necessarily occur, there is only the probability of occurrence. Therefore, we can measure the probability of the occurrence of value variables of any commodity and commodity combination in economic activities, and obtain the probability distribution of the value of relevant commodities under certain conditions. In reality, the comparison of value means is difficult and can not accurately reflect the size of value variables. We can also measure the concentration of commodity value distribution by variance. The larger the variance is, the more speculative it is; the smaller the variance is, the stronger the stability. Analogous to the mean's being the center of gravity of a distribution of value mass, the variance represents the risk. The mean and variance of portfolio value can be jointed. After suming, the mean and variance 
increase, that is, the value increases and the speculation increases.

There are various factors and influences that could determine value. We would not take into consideration the detailed elemen $t$ analysis that affects value here, as we would never be able to list them explicitly. We are only considering the probabilistic description of value; this could be influenced by the probability of the degree of recognition that people have towards objects and values. By doing this, the examination of value would not be constrained by certain factors, making it more distinct and clearer to measure value.

As the cornerstone of economics' concept, the essence of value has been explored and studied by many historical economists. However, due to the limitations of historical knowledge and mathematical tools, only some empirical descriptions are made, not quantitative descriptions. According to the theory of conditional probability, this paper constructs a value measure ment method for straightforward operation. With the general assumption of economics, this method transforms the problem of value measurement in economics into conditional probability distribution function in mathematics. The parameters of this probability distribution are calculated by collecting data through sampling surveys. The mean value is used to measure the comparative value, and the vari ance is used to evaluate the dispersion of value. This paper theoretically shows that the value of any commodities can be measured, and the value of different commodities can be compared and combined. J. M. Keynes once remarked that "the economics theory does not furnish a body of settled conclusions immediately applicable to policy. It is a method rather than a doctrine, an apparatus mind, a technique of thinking, which helps its possessor to draw conclusions." Our value measurement method evocatively develops and enriches the understanding of value, which is a thinking technique. In particular, it has an extensive application prospect in the digital economics and other fields promoted by the new generation technology represented by blockchain technology, etc.

\section{References}

1. Paul A. Samuelson, William D. Nunlhaus. Economics. 18th Edition, McGraw-Hill Companies, Inc. 4, 27, ISBN 0-07-287205-5 (2005).

2. Adam Smith. An inquiry into the nature and causes of the wealth of nations. Liberty Classics, 12, 23, 25, 72 (1776).

3. Karl Marx. Capital. (Volume I), Progress publishers, Moscow, USSR, 28, 29, 41, 47 First English edition of 1887 (4 ${ }^{\text {th }}$ German edition changes included as indicated) (1887).

4. Alfred Marshall. Principles of Economics. (London: Macmillan and Co. $8^{\text {th }}$ ed. 1920), 43, http://oll.libertyfund.org/title/1676 (1890).

5. Akira Takayama. Mathematical Economics. The Dryden Press, 3, ISBN 0-03-086653-7 (1974).

6. Sheldon M. Ross. Introduction to Probability and Statistics for Egineers and Scientistst. $3^{\text {rd }}$ Edition, Elsevier Academic Press, 59-121, ISBN 0-12-598057-4 (2004).

7. J. M. Keynes. "Introduction" (to the series), Cambridge Economic Handbooks (the first book in the series, Supply and Demand by H. D. Henderson, appeared in 1922, pubulished by Harcourt Brace and Co.).

\section{Acknowledgements}

We are very grateful to Zhuqing Huang (Qingdao), who was the first to ask what is value with us. We have had many a time discussions over the six months. In particular, we thank Yinglin Xi (Vancouver) for translating. We thank the referees for their constructive comments that helped improve this paper.

\section{Author Contributions}

Gang Xi, Xiaoyi Yang and Ming Xi initiated the research the project and wrote the paper.

\section{Competing interests}

The authors declare no competing interests.

\section{Additional information}

Correspondence and requests for materials should be addressed to G. X.

Reprints and permissions information is available at www.nature.com/reprints.

Publisher's note Springer Nature remains neutral with regard to jurisdictional claims in published maps and institutional affiliations. 
Figures
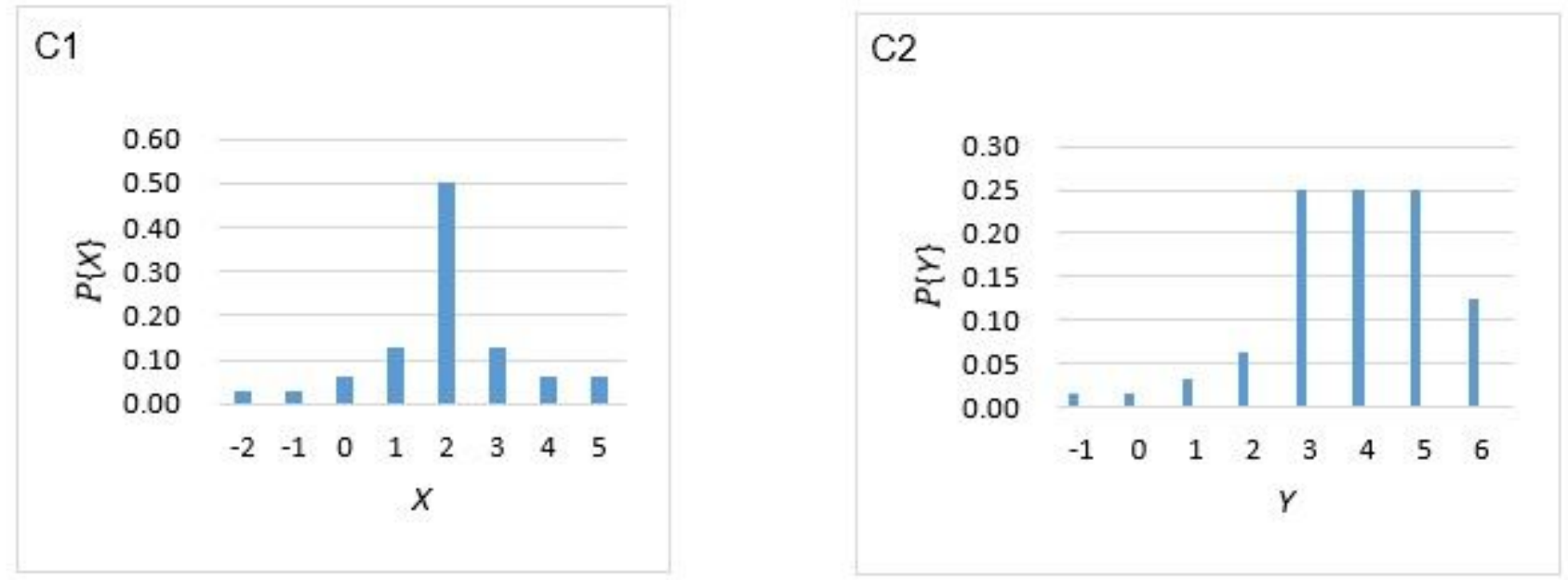

\section{Figure 1}

All possible C1's value variable $X$ is $-2,-1,0,1,2,3,4,5$ and corresponding probability distribution $P\{X\}$ is $1 / 32,1 / 32,1 / 16,1 / 8,1 / 2,1 / 8,1 / 16,1 / 16$. All possible $C 2$ 's value variable $Y$ is $-1,0,1,2 \varangle 3,4,5,6$ and corresponding probability distribution $P\{Y\}$ is $1 / 64,1 / 32,1 / 32,1 / 16,1 / 4,1 / 4,1 / 4,1 / 8$.

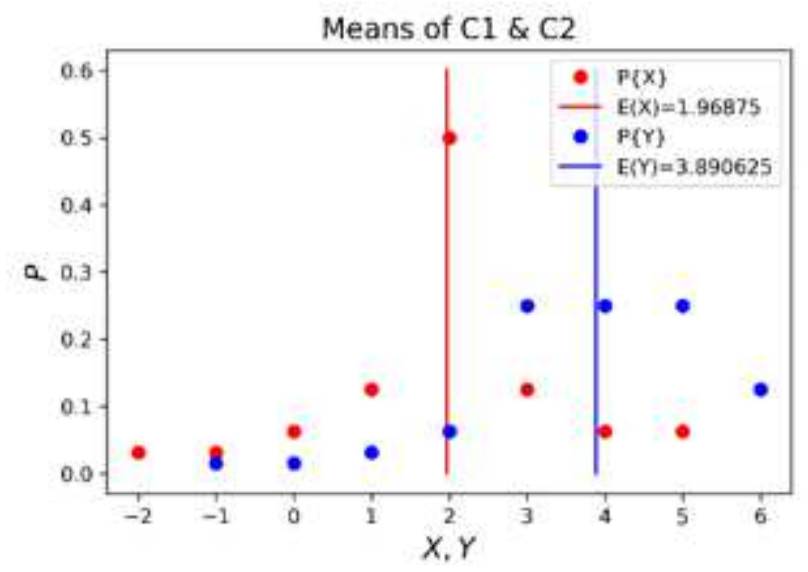

\section{Figure 2}

The value distribution of C1and C2 closely gather around the mean of value of 1.96875 and 3.890625 (red and blue line). 


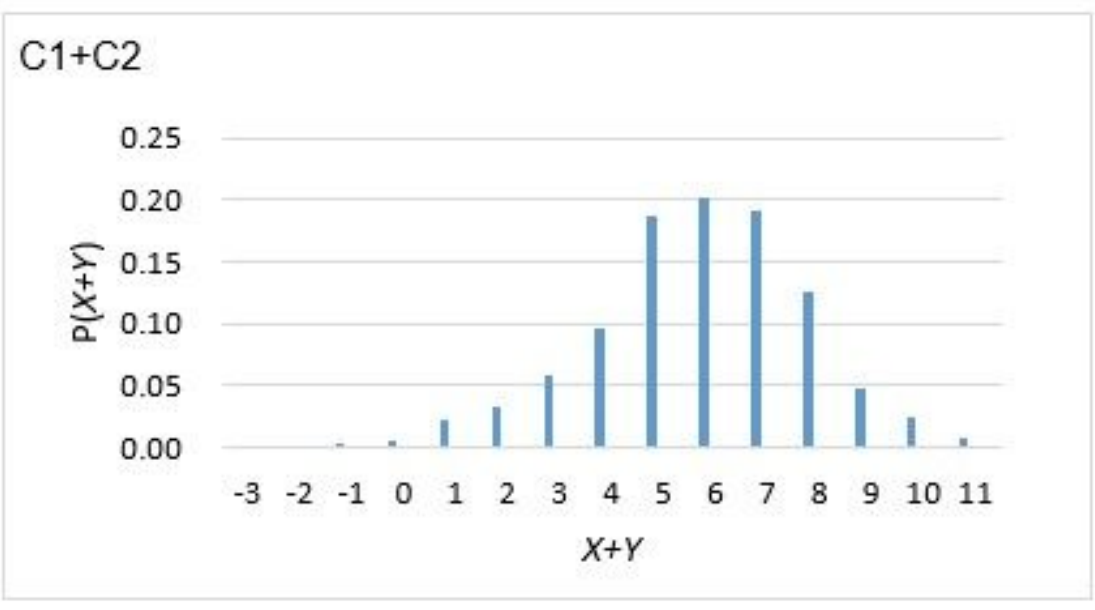

\section{Figure 3}

All possible numeric of C1+C2's value variable is-3, $-2,-1,0,1,2,3,4,5,6,7,8,9,10,11$ and corresponding probability distribution is $1 / 2048,1 / 1024,5 / 2048,3 / 512,11 / 512,17 / 512,59 / 1024,49 / 512,191 / 1024$, $103 / 512,49 / 256,1 / 8,3 / 64,3 / 128,1 / 128$. C1+C2's smallest probability is $1 / 2048$, as value is -3 ; biggest probability is $103 / 512$, as value is 6 . 